\title{
Contingent Convertible Bonds as an Alternative to Strengthen Banks' Ability in Financing a Real Economy
}

\author{
Jolanta Zombirt
}

\section{A B S T R A C T}

Objective: The main goal of this paper is to analyse whether Contingent Convertible Bonds (CoCos) are equally safe for banks and for the real economy because of their, sometimes, uneasy to understand features. It is still too early to estimate precisely an impact of CoCos for credit institutions because European Union is in the process of moving towards new regulatory framework with an aim to strengthen banks' resistance against future shocks. CoCos have not passed any serious test in this context but, from the point of banks' view they seem to be very promising. How will they behave during periods of market stresses it than has to be demonstrated.

Research Design \& Methods: Main methods are studies of the available literature, especially recommended by Calomiris \& Herring (2013) and Borio (2013). A particular attention has been paid to various models of CoCos.

Findings: My findings confirm that there are still unidentified threats connected with CoCos that could jeopardize future proper functioning of a financial system and then - a real economy. Still, if not materialized, these threats will by easily outweighed by advantages for resistant balance sheets of banks.

Implications \& Recommendations: CoCos can serve as a valuable instrument to upgrade a capital base of banks. However, it is important to make some efforts to design certain standardized features to enable comparison and valuation, to avoid unintended negative consequences for banks and economy, as a whole. Negative consequences for banks could result from overreliance on this source of capital and for economy - in a form of rescue packages from taxpayers money.

Contribution \& Value Added: My studies are an attempt of a comparison of pros and cons of CoCos. Moreover, it is an attempt to present CoCos in a broader context of banking regulations.

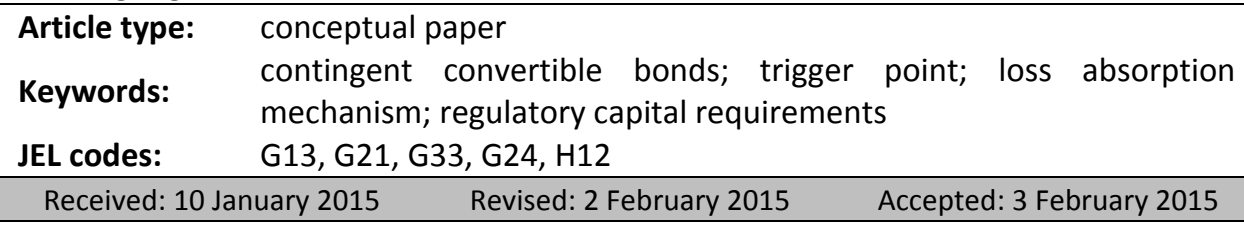

\section{Suggested citation:}

Zombirt, J. (2015). Contingent Convertible Bonds as an Alternative to Strengthen Banks' Ability in Financing a Real Economy. Entrepreneurial Business and Economics Review, 3(1): 135-149, DOI: http://dx.doi.org/10.15678/EBER.2015.030110. 


\section{INTRODUCTION}

Subprime crisis in the USA has been caused by almost entirely unknown financial instruments-mortgage-backed securities collateralised by mortgages of a doubtful quality. It has been revealed that even some institutional investors, investing heavily in these instruments, have not been aware about some unclear details of them. That is why the crisis has had the fertile soil to erupt.

The aim of this paper is to describe a relatively new (first issuances took place in 2009) financial instrument: contingent convertible bond (CoCos) that is more and more often used by banks with the aim to improve their capital position. During the period after the financial crisis $(2007+)$ regulatory authorities in the world came in with many initiatives to strengthen a resistance of banks against the future stresses. The focus of these initiatives has been put mainly on shaping new rules to increase levels of banking capital. Higher amount of own funds, in other words, a greater resistance means also greater abilities to finance a real economy. Adequate supply of loans for households and enterprises in Europe could be a chance for the quicker recovery from the recession having been a result of the crisis.

\section{LITERATURE REVIEW}

Analysing the phenomenon of CoCos seems to have been a trendy research domain since their first issuance. A growing interest among academics follows some regulatory solutions, especially Basel III recommendations; however it is not clear where exactly this concept has come from. A certain first insight could be obtained in the paper of Leland (1994), who tries to shape an optimal capital structure and for the first time mentions "triggers" as the early warning mechanisms that could prompt supervisory authorities to undertake remedial action. Then Raviv (2004) indicates how important is to maintain a market discipline by submitting a banking health in form of debt instruments to the assessment of market participants. He also mentions a subordination structure as a way to structure bulks of risk for potential investors. On this background a lot of empirical studies have been performed, for example Albul, Jaffee \& Tchistyi (2012) who developed models to derive a probability of bankruptcy from elements of a capital base of various banks. Calomiris and Herring (2013) perform a comprehensive analysis on various fundamentals to built-in properly trigger points and their work is using some conclusions of other academics and practitioners in this field, for example Duffie (2009), Segoviano and Goodhart (2009), Gersbach (2010), Miles, Marcheggiano \& Yang (2011), Flannery (2005) and others.

There is also a bulk of papers devoted to some general issues connected with, for example, early warning mechanisms on crises as Kashyap, Raghuram \& Stein (2008). Very useful findings concerning some statistical observation and rationale behind creation of CoCos can be found in papers of Bank for International Settlements, for example Borio (2013) or in documents on the website of the European Central Bank.

All these mentioned above studies and papers, however, scarcely touch a liaison between a safety and resistance of financial systems, prudential regulations and their development, as well as the potential impact of a wide variety of so called hybrid capital 
instruments. They rather focus on the separate issues listed above. So, in this paper I have tried to combine all of them to show how attractive CoCos could be for issuers and investors, how do they fit into new regulatory framework and what would be their best construction to preserve investors and at the same time to strengthen a capital base of issuers to enable them to finance a real economy.

\section{MATERIALS AND METHODS}

This paper provides a description of Contingent Convertible Bond (CoCos), a financial instrument that gains popularity among issuers, investors but also regulators, however, depending on what type of entities they regulate: issuers or investors. The main features of CoCos are trigger points and mechanisms of loss absorption. Trigger point are further divided into (i) high and (ii) low and mechanisms of loss absorption into (i) conversion for shares or (ii) redemption of principal. From the first glance CoCos look very promising but do they guarantee that the things will go as planned? Do they create only the incentives upgrading the risk management?

In this section of my text the elements of CoCos are described and analysed. It is an attempt to find the most useful and safe structure of these instruments, not only from the point of view of issuers but also of investors having various incentives and limitations to choose them.

The main goal of this paper is to analyse whether Contingent Convertible Bonds (CoCos) are equally safe for banks and for a real economy because of their, sometimes, uneasy to understand features.

The presented study aims at answering the following research questions:

RQ1: Is a contingent convertible bond an instrument equally advantageous and safe from the banks' point of view?

RQ2: Does an instrument of CoCos carry any dangers for a proper functioning of a real economy and for taxpayers' money?

This paper applies the literature review and its critics as the main research methods. The empirical part of the paper is based on the analysis of documents regulating the CoCos phenomenon in the financial markets.

\section{RESULTS AND DISCUSSION}

\section{Regulatory Benefits of CoCos and Their Profitability}

There is a huge range of reasons that have caused a subprime crisis in 2007. Among them, a high concentration of loans in banking balance sheets and problems with liquidity is being quoted. These problems could be overcome if the banks had a sufficient amount of capital of the best quality. It means that banks should always keep an eye on having adequate level of capital that could absorb losses. It means that banks should raise additional capital when needed. But, what became apparent during the last financial crisis, some banks are reluctant to issue new shares when their market value is low because it could dilute the rights of existing shareholders. And they prefer, as we have observed, to wait and see for the increase in share prices. Some of them, especially 
systematically important ones, even hope that their governments will rush with assistance (as it was the case with Bear Stearns).

In October, 2014 European Central Bank has published results of its comprehensive assessment of banks' balance sheets, i.e. 130 banks in the euro area and Lithuania, which possess roughly $85 \%$ of total bank assets in the euro area. The assessment has revealed that above mentioned banks have risen some 203 billion EUR within a year covered by review and this amount includes some 31.6 billion EUR issuance of contingent convertible bonds (CoCos). CoCos represent than the second biggest source of capital and observations of the market indicate that this source is becoming more and more attractive. It is worth to add also that between June 2009 and June 2013 total value of issuances amounted to roughly 70 billion USD (Borio, 2013). Despite the fact that a lot of potential issuers have been waiting to enter this market until ECB would publish its results, there are many symptoms that the coming months will make new records as far as the total value of issuances is concerned. Why? Because also for regulators it is important to know how rapidly banks would reach new required levels of capital, so they do not want to stem in those banks considering CoCos as still very effective and cheap way to improve their capital positions. In the environment of extremely low interest rates of the ECB, a potential yield offered by these instruments matters, too. Positive opinions are also formulated by various organisations, for example The European Securities and Markets Authority (ESMA) states that if they work as intended in a crisis CoCos will play an important role to inhibit risk transfer from debt holders to taxpayers (ESMA, 2014). The only doubt at the moment is a safety of these instruments for retail investors because they are, as the British regulator, Financial Conduct Authority (FCA), states these investors are not sufficiently educated about the risk of CoCos. Besides, some potential issuers refrain from issuances of CoCos because they are not sure what regulatory treatment they would obtain and how they would be treated in a regulatory capital structure. Equally positive should be a reaction of potential investors attracted by CoCos having higher returns of capital than of other debt securities, i.e. at least of more than 100 basis points. Spread of CoCos will however be still dependent on two features of these instruments: level of a trigger point and a mechanism of loss absorption.

So, what are CoCos? CoCos are hybrid bonds offering for their issuer an advantage to be treated as a banking capital up to $1.5 \%$ its risk weighted assets, according to the recommendations of Basel III. That is why they are also known as Basel III notes. They could be qualified as a banking capital because they can be converted into shares (Conversion into Equity, CE) or subject to total redemption (PWD, principal write-down). Rules on CoCos have been developed by Basel Committee on Banking Supervision (BCBS) and transposed into EU law by the Capital Requirements Directive IV (CRD IV) and Capital Requirements Regulation (CRR). These rules have partially entered into force from January 1, 2014. Banks are required to maintain a high quality capital equal to $8 \%$ of so called risk weighted assets (RWA). Risk weights are assigned to particular assets according to the methodology, i.e. depending on what approach of RWA calculation in a given bank would be accepted by supervisors. If than a bank can use so called Standardised Approach (SA), it will assign a risk weight on the base of a defined rating assigned by recognised external rating agencies. Or, if a bank is allowed to use so called 
Internal Rating-Based Approach (IRB), it will calculate risk weights derived from its risk models.

We can then see that a safety, soundness and resistance for stresses in banks are closely connected with a quality of regulatory capital. In legal acts above mentioned it is clarified - after the experiences of the last financial crisis - how a capital of the highest quality should look like. Such a capital of own funds of banks should have the highest abilities for loss absorption, then - a capital to cover the losses in the first instance. Such a capital, according to the Basel terminology, is called Common Equity Tier 1 (CET 1) that has to amount to at least $4.5 \%$ of risk weighted assets. The aim of the European legislator was then to increase a capital layer of banks in form of paid-in common shares whose capital would be rapidly available in the case of losses. CRR considers, however, a possibility to permit a given credit institution to issue financial instruments qualified as so called Additional Tier 1 (AT 1), or supplementary CET 1, for example in form of CoCos to the amount, as it has been mentioned, 1.5\% RWA, so to obtain a total Tier 1 at least $6 \%(4.5 \%+1.5 \%)$. CRR allows also recognising CoCos as elements of so called Tier 2 , to obtain a total amount of bank's capital at least $8 \%$ of RWA. Difference between CoCos that can be included in CET 1 and these included in AT 1 is that in the former case the activation of a loss absorption mechanism starts earlier what is defined as CoCos with high trigger point (let's say, below 7\% core Tier 1 ). It means that an activation of mechanism is being created earlier so it is more desirable from the point of view of issuer's safety and at the same time more risky for investing in CoCos. In other words, CoCos with a low trigger point have a lover ability to absorb losses so they are less valuable from the point of view of a regulatory capital.

For banks it is of course not neutral whether CoCos issued by them would be qualified as Tier 1 or Tier 2 capital. From banks' point of view the most advantageous is recognition of CoCos as Tier 1 capital because it diminishes an obligation to supplement Tier 1 capital by issuance of new common shares. An issuance of new shares could be after all not accepted by existing shareholders because of dilution of their rights. An obstacle could also be created by costs of an issuance: a level of coupon paid by CoCos that could be qualified as CET 1 can be too high to be accepted by an issuer. For an issuer, because of the costs, a better solution will be to supplement AT 1 capital by CoCos with a low trigger point. Besides, observation of markets from 2012 indicates that costs considerations prevail and there are more CoCos qualified to AT 1 capital.

Generally, to qualify for Tier 1 capital or, as it has been said, for capital of the best quality, CRR states that CoCos have to carry a possibility to redeem all or a part of a principal or be subject to an automatic conversion for shares in a strictly defined moment. This moment in regulations is defined as a trigger point and it describes a situation expressed in numbers when a value of CET 1 capital decreases in relation to RWA. For regulators and some potential issuers or investors a problem exists because various CoCos could have different criteria for activation of trigger points what makes them extremely difficult to compare. Besides, it is worth to indicate that the present rules do define it indicating only a minimal level of a trigger point and relating this problem to specific features of an issuer. That is why there is a considerable spread of levels of trigger points among observed issuances: from $5.125 \%$ to $8.25 \%$ ratio of CET 1 capital to RWA. 
A possibility to redeem of a part or all principal or conversion for shares is defined generally as a mechanism of loss absorption. But also in this case there is a considerable variety, in relation to their structure (even in CoCos issued by entities in the same banking group) or in relation to an uncertainty about interpretation by relevant supervisory authorities as concerns reaching a trigger point, so reaching a moment to activate a mechanism of loss absorption. A trigger point mentioned above on a level $5.125 \%$ is being derived from Basel III and it is a minimal level. So it is not surprising that issuers more and more often decide, however, to issue CoCos just on this level or close to it because of the lower costs that CoCos recognised as CET 1 capital. It is worth to note here that costs considerations have also the influence on a choice what mechanism of loss absorption will be embedded in CoCos: CE or PWD. A risk of conversion of CoCos into shares is usually a better option for an investor than redemption of principal. So investors in CoCos CE will require a lower premium. However, a problem exists that some institutional investors do not have a regulatory mandate to invest in shares (or their substitutes as CoCos). So they will be more interested in purchasing CoCos PWD. It is also important because of mentioned environment of low interest rates of ECB and seeking a higher return of capital by investors.

The influence on a choice of mechanisms of loss absorption could also have a various tax treatment of CoCos in various jurisdictions. These instruments are not recognised as debt everywhere and interests paid on debt do not everywhere diminish an income tax paid by issuer.

Basel III requires also that CoCos qualified as CET 1 or AT 1 capital should be perpetual, i.e. they cannot have a defined maturity. So, the first issuances constituted a debt without maturity and only some years ago we have seen CoCos with stated maturity, most frequently to 10 years. However, in this case these instruments can be recognised only as $\mathrm{T} 2$ capital.

It is especially important from the investors' point of view because they have yet exposure on risk of loss of their investment. It is then a challenge for them to properly model a probability of losses (in Basel terminology - probability of default, PD) when activating of trigger points. It is not only dependent on a risk profile of an issuer but also on its future abilities to supplement a regulatory capital or sensitivity on losses occurring at its counterparties (risk of contagion). As it can be seen, modelling of this sort of risk requires an experience and technical abilities at investors. So, the British supervisory authorities (and ESMA) are right when they are of the opinion that CoCos should be offered only for institutional investors.

It is worth noting that such investors should have skills and knowledge about details of regulatory capital framework, and, more precisely, what elements are qualified as CET 1 or AT 1 capital and what is a structure of assets' portfolio of an issuer from the perspective of dangers generated by them (maturity or risk weights assigned to particular assets) and its dynamics. In other words, investor should have information on permanently changed value of CET 1 capital and its potential "distance" from a trigger point to assess a risk of conversion or redemption of principal. It is then important to remember that these changes in CET 1 capital will be generated by losses resulting in decrease of a regulatory capital or by an increase of risk weighted assets. Additional risk is moreover embedded in CoCos recognised by supervision as At 1 capital. The idea is 
that in this case an issuer has an entire freedom in making decisions about principal redemption from these instruments, in any moment, in any amount, because of any reason and for unknown period. If it happened that capital from AT 1 is being submitted to redemption for a certain period, payments from coupons will be not cumulated but... amortised. It is important to add that such a situation could happen even when an issuer still pays dividends for its shareholders or a floating part of remuneration for its staff. It means that in a subordination structure of loss absorption CoCos will be treated as subordinated in relation to common shares.

\section{Structure of CoCos}

As it has been said, CoCos are instruments that have features resembling common shares and as such should have embedded mechanisms of loss absorption by capital redemption or conversion for shares. Such an action should happen not later that reaching by an issuer a state of insolvency. A moment of conversion or redemption is defined individually for any issuer because it depends on an amount of its capital. Moreover, mechanism of conversion or redemption has to be credible and resistant for any attempts of manipulations of share prices of an issuer.

From the point of view of safety of bank issuer it is very important to precisely define a point of conversion or redemption, because it has to meet two goals: (i) implementation in a bank of credible systems for management and measurement of risk and (ii) to raise a fresh capital or timely reduction of assets. It is worth to note here that nobody knows what amount of capital would be sufficient for banks to withdraw losses. And, excessively severe capital requirements would increase costs for banks and curb their willingness to advance loans for a real economy. So, CoCos should have embedded some incentives for banks to upgrade their systems of risk assessment and management. A measure of a share capital used by Basel is just an accounting one underestimating a real economic value of capital that leads to problems with timely losses' recognition (Calomiris \& Herring, 2013). It then seems to be a unique opportunity for regulators and supervisors to precisely design an instrument that would force bankers to analyse on a daily basis the performance of their relevant business lines and assets. And without any doubt, financing by issuances of debt, instead of shares, has a potential to increase a market discipline among issuers and to upgrade their system of risk management, to set an appropriate level of regulatory capital and to timely replace lost capital (what is, from the regulatory point of view, a main goal).

As it has been said, a moment of redemption or conversion should be known in advance by investors and it is defined as a trigger point. Reaching of a trigger point could be caused by events described above automatically, by reaching the predefined given capital ratios (ratio of own funds to risk weighted assets), and here a value of own funds can be defined as accounting or market value, or on a base of a discretional supervisory decision. What is important, in a construction of CoCos one can insert more than one trigger point.

A trigger based on capital ratios would activate a mandatory conversion if a Tier 1 capital ratio falls below a threshold specified either by regulators or in the contractual terms of the contingent capital instrument itself (Pinedo \& Ireland, 2014).

If for a design of a trigger point one uses an accounting measure, than it is important to know how frequent updates of elements of a capital ratio (i.e. issuer's capitalisation) 
will be performed, and also to assess a credibility of internal models being a fundament to calculate risk weighted assets. Frequency and quality of financial reporting seem to be in this context of the utmost importance. For example, Lehman Brothers reported just close to its bankruptcy about its capital ratio $\mathrm{T} 1$ on a level $11 \%$, well above the regulatory minimum (Pinedo \& Ireland, 2014). Or, the British supervisor, FSA, recognised as one of the most effective in the world, failed to assess properly a financial health of Northern Rock. Just few weeks before a bankruptcy of this bank FSA has issued the approval to use in NR an AIRB for risk weights of its mortgages which helped to reduce its regulatory capital by $30 \%$ and pay it off to its shareholders (Calomiris \& Herring, 2013).

However, despite certain shortcomings with the approach based on an accounting value it seems, from the point of view of predicted activation of a trigger point, that is a solution safer that one based on a market value (it is nevertheless important for CoCos to be set at the possible high percentage of an accounting value, especially for ones with CE option). A market value is clearly more difficult to set because of various market situations, for example high volatility of prices or market manipulations (ex. short selling of issuer's shares). A trigger based on market metrics would force a mandatory conversion, for example, if the issuer's share price or CDS spread passes a certain level over a set period of time (Pinedo \& Ireland, 2014). However, prices of shares, if used property, would supply valuable information about condition of an issuer. Conventional wisdom is that markets react pretty earlier than supervisors. For example, some wellknown failures of big companies that have surprised rating agencies and regulators were signalled earlier by sharp and persistent decrease of a market value of their shares (WorldCom or Enron). The same can be observed when a market value of Lehman Brothers is concerned. So, if supervisors have ordered Lehman to issue CoCos with trigger based on a market value of its prices then such a fall in market price would trigger a conversion of debt into shares long before its insolvency (Calomiris \& Herring, 2013). Of course, a certain range of a market volatility of prices is a normal feature in the markets. So, to property define a trigger point based on a market value it would be useful to observe the process during a certain period, say, 90 days to smooth observed data.

When an activation of a trigger point on a base of a discretional decision of supervisors is concerned, it is also a problem for potential investors because they could have difficulties with an assessment of a moment of such a decision - or, of a moment of activation of a mechanism of loss absorption. However, from a point of view of an experienced investor, able to draw adequate conclusions from information publicly available by an issuer, these difficulties could prove negligible as far as an investor possesses knowledge about a systemic importance of an issuer, i.e. how a risk of its insolvency could jeopardise all the financial system. It is worth to note that just these difficulties with an assessment of a moment of making a discretional decision have been underlined by one of the rating agencies. Because of this the cited agency has refused to assign a rating for CoCos with conversion dependent on regulatory decision or of bank's management (Calomiris \& Herring, 2013).

As it has been said, CoCos are issued to improve a quality of an issuer's capital and in this way to foster its resistance for losses. In other words, an investor purchasing CoCos agrees to take on risk of loss of its investment in an event of losses at an issuer or to 
become a shareholder of this issuer as the effect of conversion CoCos into shares. A mechanism of loss absorption consists then in, from a technical point of view, on an improvement of a capital position in CET 1 capital either with a conversion in a predefined trigger point, or with a coverage of losses with funds obtained from CoCos what surely translates into a loss for an investor, proportionally to the losses of an issuer.

Trigger point releases, as it has been said, a mechanism of loss absorption. With conversion of CoCos for shares a ratio of conversion is defined - by now - in three different ways. It then could be a share price in the market in the moment of reaching a trigger point, share price defined earlier (for example, share price in an initial offer) or a combination of these two. This third solution seems to be optimal from the point of view of potential and existing shareholders, because the former would have a chance to become shareholders having paid an attractive price for a share, and the existing shareholders would have better incentives to avoid reaching a trigger point, so to a better insight in management of an issuer's balance sheet and with it they could avoid a dilution of their rights to the benefit of the new shareholders.

\section{Pros and Cons of CoCos}

Advantages of CoCos have been a subject of widespread interest and that is why their popularity among issuers is growing (Martynova \& Perotti, 2013):

- Properly designed CoCos can induce risk reduction.

- There exists an optimal CoCos amount that minimizes risk.

- The trade-of is between equity dilution and CoCos dilution effect.

- The banker never willingly chooses CoCos over deposits.

When asset risk and trigger precision are high, CoCos may be safer and thus cheaper than traditional bonds.

- A higher amount of contingent capital is required to provide the same effort incentives as equity.

- A dual trigger may be optimal, to filter out market manipulation while challenging forbearance.

Advantages described above can also be supplemented with a unique accounting benefit. The point is that in contrast to other convertible bonds it is not necessary to account them in an income for a share as long as they are not converted into shares. Moreover, in United Kingdom and USA interests on loans are not taxed, so less issued shares, the greater profit for one share.

Although it is desirable for all banks to complement their capital by issuances of CoCos it is more important, from a point of view of a systemic risk, to give such an opportunity for systematically important financial institutions (SIFI). It is worth noting that Basel III does not permit G-SIFI (global systematically important financial institutions) to use CoCos as an additional source of regulatory capital. However, it is allowed when CoCos are used to meet additional national requirements. So it should be considered as the positive phenomenon that some bigger European banks have issued CoCos or are going to do this. It does not mean that CoCos are not an attractive option for smaller, peripheral banks. For example, Spanish Banco Popular became in 2013 the 
first peripheral bank of a medium size that issued CoCos. Other banks from Spain and Italy have followed it (Figure 1).

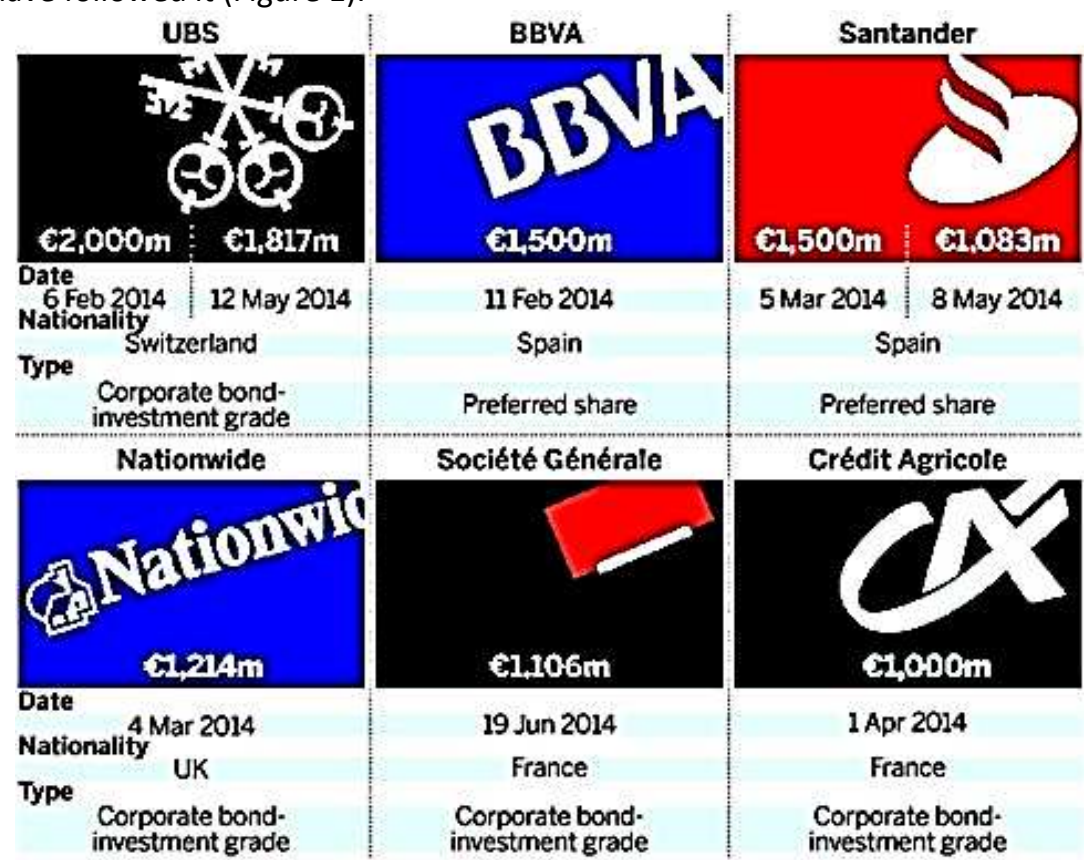

Figure 1. Contingent Convertible Bonds. Biggest European Deals

Source: Coco sell-off unveils high-yield bargains. Retrieved on August 14, 2014

from http://www.ft.com/intl/cms/s/0/e9d5ffca-2308-11e4-a424-00144feabdc0.html.

However, in the literature there are also many threats carried by CoCos (Freixas, 2013), for example, if they are triggered by market price:

- Possibility of multiple equilibriums,

- Death spirals (CoCos with a built-in PWD option),

- Price manipulation through derivative markets,

- CoCos holders may prefer bankruptcy.

From a point of investors' view CoCos serve as a kind of a protective cushion between shareholders (who should make losses in the first place) and holders of the most sensorial tranches of bonds.

But... is it safe to invest in instruments that have not been tested by the market and that are an issue of concern for rating agencies? Do they really offer a guarantee of a better capitalisation and a better protection against losses in banks? As some observers indicate (Greeley, 2013): "We've seen this magic trick before. In 1996 the U.S. allowed what it called "trust-preferred securities," a kind of low-class debt, to count as Tier 1 capital. If a bank became insolvent, this debt would be the first to become worthless. During testimony to Congress In 2011, Sheila Bair, then chairwoman of the Federal Deposit Insurance Corp., explained that "our experience with these instruments during the crisis is that they impeded recapitalizations [she means that banks that used these 
securities failed to get more equity when they needed it] and that institutions relying on them were generally weaker and more likely to be engaged in high-risk activities."

The "only" difference between "contingent capital" and "bail-in capital" is that a contingent capital is being activated after reaching a certain predefined trigger point sometimes well before a given institution gets bankrupt or starts a resolution. Bail-in capital is being activated by national resolution authorities when a failing institution enters a resolution process or becomes insolvent. The problem is that before an institution reaches a trigger point (what is sometimes difficult to predict) it could decide not to pay interests for CoCos investors despite the fact that it can still pay dividends for shareholders. So, knowing a huge possibility for financial institutions to shape their balance sheet in the way to give comfort for their investors, the opportunities to circumvent certain "paper" or easy to free interpretation rules it seems to be a great probability that some institutions would use CoCos as a tool to protect their shareholders when losses come. The regulatory option that "the write-down of principal could either be permanent or it could include a write-back feature if the issuer regains its financial health" (Pinedo \& Ireland, 2014) is not specially convincing, especially because a point of "regaining financial health" is not precisely defined. One has to remember that most decisions in a company are undertaken by its shareholders, not regulators. And, if the existing shareholders have something to loose they will surely shift this burden on investors in CoCos.

So, in times of cheap money offered by ECB and a kind of regulatory pressure on banks to increase their capital base one should assume that the real economy would benefit from cheap loans. Nevertheless, on the other hand, we see also entities starving for higher return of their investment. That is why they are ready to accept higher levels of risk. Banks do not only play a role of lenders, they are sometimes investors as well. When the matters go as they predict they can earn a good yield. But when situation worsens they could end with empty pockets. I am afraid that CoCos have the potential to repeat a collapse of a financial system as it was the case in the U.S. subprime crisis. It had its roots in the environment of easy money at the beginning of this century and after 5 6 years a crisis has erupted, the greatest one since the Great Depression. So I am not especially impressed with an apparent regulatory willingness to push banks to issue CoCos. Of course, they want to protect the taxpayers' money and they will welcome issuances of CoCos, especially by banks having been recipients of huge amounts of public funds, as British Lloyds in 2009. But there is also the other side of the coin: if the issuers exercise their option for, say, PWD in a face of their difficulties and such decision brings given investors to bottom, who will have to rescue them?

\section{Perspectives for CoCos Market}

Generally, at present, demand for such bonds is "seen as low because of the risky features of these securities and bad loans add to the problem" (Patil, 2015). Basel III notes are considered risky because of the write-down or conversion features they contain that are triggered by a certain event or at the point of non-viability (Patil, 2015). Until now, at the primary market of CoCos the most visible were the retail investors and banks from Europe and Asia (52\% demand for CoCos), then U.S. institutional investors and also non-banking financial institutions from Europe. 
But the most influential group of investors who would stimulate a further growth of CoCos market is a group of institutional investors. It is inter alia because, at it has been mentioned above, some regulators have prohibited, or consider it, to offer CoCos for retail investors. However, institutional investors often face some regulatory limits on investing in certain instruments. Moreover, the most common limit is a prohibition to invest in securities without rating or with rating on a level close to speculative. Lack of a broad spectrum of ratings constitutes also an obstacle for including these securities into indices of debt instruments what is a further limitation for attracting of institutional investors. Shortcomings with ratings are linked however with difficulties the rating agencies have to cope with. How, for example, to assess uniformly CoCos issued in various jurisdictions so - with various tax regimes? How to assess levels of subordination, one of the most important aspects taken into account by investors, influencing on an order of bond holders' satisfying in an event of losses? "Stratification", one of the most important features of securitisations, or dividing into tranches, seems to be the best indicator of risk for investors. Similarly, it would be very important for investors in CoCos, or still even more important because in this case there is a risk that CoCos holders will suffer losses as first among investors having other securities issued by the same issuer, even before shareholders (for CoCos with a high trigger point). Moreover, a difficult question for rating agencies is an existence of various ways to activate mechanisms of loss absorption, among others, activation on a base of a discretional decision of supervisors. So it is not a surprise that at the beginning CoCos have not carried ratings (nowadays without ratings there are slightly more than half of outstanding issuances) but slowly agencies started to weigh out to assign ratings only for CoCos with a low trigger point. Moreover, methodology of some rating agencies requires for CoCos to have rating not higher than $\mathrm{BBB}+$ that could not be accepted by some investors because of regulatory considerations. Such a rating will be also lower than all other debt instruments issued by the same issuer.

Moreover, in the case of CoCos there is a conflict of interests between issuers' regulators and investors' regulators. From the point of view of the former issuances of CoCos bring benefits because they supply an issuer with a fresh capital capable to absorb losses. Such a potential to absorb losses is worrying investors' regulators - it exposes them to a greater risk of losses than in a case of investments in other debt instruments. An evident conflict of interests exists also between shareholders and holders of CoCos of the same entity, what has been indicated above. This problem is called "dilution" or, in other words, diminishing of a value of shares possessed by existing shareholders. Conflict of interests in this case is such that existing shareholders prefer issuance of CoCos with a high trigger point because it means that reaching this trigger activates a mechanism of loss absorption in a moment when a share price is still relatively high while investors in CoCos prefer a low level of a trigger point because it carries a greater probability that an activation of a mechanism of loss absorption will not happen. Another type of a conflict of interests between existing shareholders and potential investors could be a structure of a mechanism of loss absorption (mentioned above a trade-of between CE and PWD). Investors would prefer eventual conversion of CoCos into shares while existing shareholders - PWD. But it does not concern all investors because, as it has been mentioned, some institutional investors have regulatory limits with investing in shares, 
so for these investors a PWD option could be attractive. So, despite the fact than, generally, CoCos with a CE option could be safer, a PWD option, as an option with more risk promises to give a higher return of capital (YTM, yield to maturity), in average, by two percentage points.

When an YTM is being concerned we should pay attention on a valuation of CoCos according to levels of a trigger point. As it has been said, a higher trigger point is riskier from a point of view of an investor - so it will be more expensive for an issuer. In sum, for an issuer an optimal solution will be to offer CoCos with a low trigger point and a CE option. As it emerges from market information, just a difference between high and low trigger point gives spread in favour of the high trigger point on a level around 1 percentage point.

\section{CONCLUSIONS}

At the onset of subprime crisis (2007) there was a huge variety of opinions about the roots of financial turmoil that has caused collapse of previously the most active markets in the world. As it has been mentioned at the beginning of this paper, many academics, market participants, regulators and supervisors keep indicating on gaps in regulatory framework, lack of responsible behaviour of banks' managers paying attention rather on return of capital than on proper capital and risk management, and also on an excessive reliance on external ratings that has led to heavy investments in opaque instruments without a necessary due diligence. But also in the first months of the last crisis one could hear shocking opinions that ... it was just a financial crisis and it could not make any harm for a real economy. Time showed that health of any financial system and of real economy is strongly interlinked. It would be difficult to imagine that a real economy could exist without its backbone - financial intermediaries.

Subprime crisis has had its main cause in, as it has been said, securitisation products known for some thirty years. These instruments have gained their popularity after publishing by the Basel Committee its first set of recommendations (1988) because by many banks they have been seen as a gate to escape from tight regulatory capital requirements. They have also offered new investment opportunities for investors because they have usually carried the highest rating (because of their unique structure) comparable with ones of sovereign debt but could offer slightly higher interests. The second Basel set of recommendations (2004) has tried to somehow "tame" securitisation by adding new requirements but ... those recommendations have been translated into national law two-three years later what has been coincident with the start of the crisis. Regulators then have made a lot of attempts to update rules on securitisation and to make them more stringent. So, it is not a surprise that financial sector, one of the most innovative in the world, has responded in many ways to invent new instruments and techniques enabling them to be compliant with new rules and - at the same time - to earn a desirable return of equity.

Regulators, as we can see, react for the news in the markets with a certain delay. When securitisation started to be treated - because of new rules - as something too expensive, too complex and, to the certain extend, obsolete technique to obtain a relief within the regulatory capital framework, a new instrument has emerged - contingent convertible bond. This instrument is being equally accepted by banks - issuers and by 
regulators because of its attractiveness. The most attractive features are: upgrading a capital position of banks as a response for new capital requirements, a problem that is being seen as a precondition for banks to respond for challenges from failing economy. CoCos seem also to be an ideal investment opportunity. So history repeats itself. When the financial world went mad with securitisation, at the turn of the century, one could hear only minor warnings about this technique. These warnings have covered mainly the problems with information asymmetry between issuers and investors, complexity and necessity to use securitisation techniques only as a tool for risk management. And - as the latest news from European Commission and European Central Bank indicate securitisation, if properly used, could be a valuable in stimulating recovery of European economy. The problem is that this expression "if properly used" cannot be fully defined.

\section{REFERENCES}

Albul, B., Jaffee D., \& Tchistyi, A. (2012). Contingent convertible bonds and capital structure decisions, University of California, Working Paper.

Borio, C. (2013). International banking and financial market developments. BIS Quarterly Review, September, CoCos: a primer.

Calomiris, Ch.W., \& Herring, R.J. (2013). How to design a Contingent Convertible Debt Requirement that Helps Solve Our Too-Big to Fail Problem. Journal of Applied Corporate Finance, 25(2), 39-62.

Duffie, D. (2009). Contractual Methods for Out-of-Court Restructuring of Systemically Important Financial Institutions. Submission Requested by the U.S. Treasury Working Group on Bank Capital, Draft of December 9, 2009.

ESMA (2014). [online] CS 60747 Statement: Potential Risks Associated with Investing in Contingent Convertible Instruments. Retrieved on November 18, 2014 from: <http://www.esma.europa.eu/system/files/2014-944_statement_on_potential_risks_ associated_with_investing_in_contingent_convertible_instruments.pdf>.

Flannery, M.J. (2005). No Pain, No Gain: Effecting Market Discipline via Reverse Convertible Debentures. In H.S. Scott (Ed.), Capital Adequacy beyond Basel: Banking, Securities, and Insurance (pp. 171-196), Oxford: Oxford University Press.

Freixas, X. (2013). [online] Ex post resolution and ex ante incentives. Retrieved on November 18, 2014 from: <https://www.ecb.europa.eu/events/pdf/conferences/130626/Session2_Freixas. pdf?b1b9a44a5457f56d52653ee5f2cb353a>.

Gersbach, H. (2010). Can Contingent Contracts Insure Against Banking Crises? The Swiss Federal Institute of Technology, Working Paper.

Greeley, B. (2014). [online] Barclays Wells Contingent Capital. What's Contingent Capital?, Bloomberg BusinessWeek, April 5, 2013. Retrieved on November 18, 2014 from: http://www.businesweek.com/articles/2013-04-05/barclays-sells-contingent-capital-dot-what -s-contingent-capital?>.

Kashyap, A., Raghuram, R., \& Stein, J. (2008). Rethinking Capital Regulation. Federal Reserve Bank of Kansas City. Symposium on Maintaining Stability in a Changing Financial System, 21-23 August 2008.

Leland, H.E. (1994). Corporate debt value, bond covenants, and optimal capital structure. Journal of Finance, 49(4), 1213-1252. 
Martynova, N., \& Perotti, E. (2013). [online] Convertible Bonds and Bank Risk-taking. Retrieved on November 18, 2014 from: <https://www.ecb.europa.eu/events/pdf/conferences/130626/ Session2-Martynova.pdf ?312e04bc244e49fb2e8e80083ec9e242>.

Miles, D., Marcheggiano G., \& Yang J. (2011). Optimal Bank Capital. External MPC Unit, Bank of England, Discussion Paper, No. 31.

Patil, D. (2015). [online] Basel Bonds Set to Spike as Bad Debt Spoils Indian Equity. Bloomberg BusinessWeek, January 1. Retrieved on November 18, 2014 from: <http://www.businessweek. com/news/2015-01-01/basel-bonds-set-to-spike-as-bad-debt-spoils-indian-equity>.

Pinedo, A.T., \& Ireland, O.I. (2014). [online] Banking in the 21st Century: Navigating Uncharted Waters. New York Law Journal, Frequently asked questions about contingent capital. Retrieved on November 18, 2014 from: <http://media.mofo.com/files/Uploads/Images?FAQsContingent-Capital.pdf.2014>.

Raviv, A. (2004). Bank Stability and Market Discipline: Debt-for-Equity Swap versus Subordinated Notes. The Hebrew University Business School, Working Paper.

Segoviano, M.A., \& Goodhart, Ch. (2009). Bank Stability Measures, IMF, WP/09/4.

\section{Author}

\section{Jolanta Zombirt}

Jolanta Zombirt is Associate Professor at the Institute of European Studies at the Jagiellonian University (Kraków, Poland). She has worked for more than 20 years in various commercial banks and also in the National Bank of Poland (NBP), and as a representative of NBP in the Working Group of Banking Development at European Central Bank (ECB) in Frankfurt am Main. She has published over 200 publications and served as an expert in the financial law, especially of regulatory capital requirements and securitisation, in various governmental institutions. She has been also advisor of the Minister for European Integration.

\section{Correspondence to:}

Prof. UJ dr hab. Jolanta Zombirt Jagiellonian University

Faculty of International and Political Studies Institute of European Studies

ul. Jodłowa 13, 30-252 Kraków, Poland jolantazombirt@gmail.com

\section{Copyright and License}

This article is published under the terms of the Creative Commons Attribution - NonCommercial - NoDerivs (CC BY-NC-ND 3.0) License http://creativecommons.org/licenses/by-nc-nd/3.0/ 
